Article history:

Received: 15 January 2020;

Revised: 31 January 2020;

Accepted: 5 February 2020;

Available online: 15 February 2020

\title{
Sebuah Model Riset Persepsi Nilai Dan Keputusan Pembelian Produk Kopi Wanaal (Papua Coffee)
}

\author{
Elizabeth $^{1}$ \\ Universitas Budi Luhur \\ gintingelizabeth@gmail.com
}

\begin{abstract}
Abstrak
Merancang strategi promosi sangatlah diperlukan untuk memasarkan produk yang sebelumnya sudah ada dipasaran dengan jenis yang sama, Kopi Wanaal merupakan jenis kopi yang tumbuh di kota Sarmi, Papua. Pada awalnya kopi di Tanah Papua ini hanya terdapat dua daerah utama penghasil kopi yaitu lembah Baliem dan lembah Nabire, namun seiringnya waktu, tumbuh pula di daerah lain di Papua yang menghasilkan kopi, salah satunya di kota Sarmi. upaya untuk mengetahui preferensi konsumen terhadap jenis kopi wanaal ini maka diperlukan sebuah model riset persepsi nilai yang dihasilkan dari penggabungan jawaban para konsumen atau penikmat kopi. Penelitian ini dilakukan menggunakan analisa conjoin dengan harapan muncul sebuah komposisi yang tepat atas produk kopi wanaal ini untuk dijadikan sebuah rumusan awal untuk metode pemasaran yang tepat terhadap segmentasi pasar yang ada. Oleh karena itu dalam penelitian ini, 100 orang dijadikan sampel untuk kemudian jawaban yang diberikan diolah menggunakan SPSS dan dimasukkan dalam analisa konjoint. Dari 100 orang tersebut dihasilkan sebuah kesimpulan utama terkait model riset persepsinya yaitu dengan persamaaan $r_{i}=13,354+$ $0,053 \mathrm{x}_{11}-0,056 \mathrm{x}_{12}+0,002 \mathrm{x}_{13}+0,281 \mathrm{x}_{21}+0,561 \mathrm{x}_{22}+0,842 \mathrm{x}_{23}+0,042 \mathrm{x}_{31}+0.084 \mathrm{x}_{32}+$ $0,127 \mathrm{x}_{33}$. Dari model riset itupula diketahui tingkat utility yang terletak pada atribut cita rasa sebesar 47\%, hal ini menandakan bahwa kopi wanaal ini mampu bersaing ditengah pasaran dengan kopi jenis dan merek lainnya yang telah beredar dipasaran.
\end{abstract}

Kata Kunci: Preferensi, Konsumen

\section{Pendahuluan}

Meneliti tentang riset persepsi nilai dan keputusan pembelian mempunyai ruang lingkup yang cukup luas seperti proses atau tahap awal bagaimana konsumen membeli hingga bagaimana para konsumen membeli dan alasan untuk akhirnya memutuskan membeli, semua tahapan ini terurai dengan jelas dalam lingkup marketing bahkan perilaku konsumen itu sendiri. Berbagai atribut yang tergabung dalam karakteristik konsumen baik berdasarkan variabel demografis, psikografis dan variabel perilaku dapat menghasilkan informasi yang sangat membantu pihak marketer dalam memahami keinginan konsumen (Ali, 2014). Karakteristik konsumen ini menjadi dasar dalam proses pembagian sebuah pasar menjadi beberapa kelompok pembeli yang bersifat heterogen menjadi kelompok yang homogeny dimana para konsumen dapat membelanjakan

${ }^{1}$ Korespondensi: Elizabeth, Universitas Budi Luhur. gintingelizabeth@ gmail.com 
sumber daya yang mereka miliki untuk barang-barang konsumsi tidak hanya sesuai bagi keinginan dan kebutuhan tetapi juga karakteristik pembeli yang ada dipasar tersebut.

Selain hal diatas, dalam lingkup marketing, merek sebuah produk atau jasa tidak hanya mencirtobagi produk atau jasa tersebut, dalam penelitian ini, produk kopi dengan merek wanaal papua cofee inilah yang dijadikan sebagai tolak ukur obyektifitas sebuah merek produk yang dikembangkan dengan strategi pemasaran untuk mencapai tujuan yang beragam. Jenis kopi yang termasuk dalam golongan kopi Arabica ini dikemas dengan menarik dan telah beredar di pasar terutama di Provinsi Papua. Aroma khas yang terdapat pada jenis kopi wanaal papua coffee ini mampu membuat ciri pembeda dan daya tarik tersendiri para penikmat kopi pada umumnya. Agar jenis kopi wanaal papua coffee ini dapat bersaing dengan jenis merek kopi lain pada umumnya, maka sangat diperlukan sebuah jalinan koordinasi pada berbagai unit kegiatan marketing yang tidak hanya dapat menambah nilai merek pada merek tersebut tetapi juga sampai pada branding produk secara keseluruhan.

Setiap produk dalam lingkup marketing pula harus mampu memperlihatkan kekuatan atributnya sendiri, atribut yang diperlihatkan tersebut pada hasil akhirnya akan memeiliki sebuah korelasi konsekuensi terhadap ekuitas merek dan preferensi konsumen terhadap merek. Untuk itu jika ingin melihat branding produk kopi merek wanaal papua coffee ini maka diperlukan beberapa atribut sebagai tolak ukur yang menjadi dasar pengukuran dalam melihat seberapa besar nilai yang dihasilkan dari atribut tersebut dengan kaitannya pada keputusan pembelian produk kopi tersebut. Dengan kata lain, nilai yang dihasilkan tersebut diharapkan menjadi sebuah preferensi konsumen yang dapat bertahan secara dominan meskipun ada kondisi perubahan di dalam lingkup pasar. Preferensi konsumen yang baik biasanya merupakan sebuah ciri penanda dimana merek dari produk tersebut dapat bersaing di pasar, selain itu tiap konsumen pada dasarnya mempunyai dasar pertimbangan yang unik ketika mulai hendak membeli suatu produk, bagi sebagian besar konsumen, kualitas barang merupakan hal yang utama, meskipun pada kenyataannya konsumen tersebut menyampingkan aspek harga yang melekat pada produk tersebut, namun pada sudut pandang yang lain, ada juga konsumen yang lebih melihat pada harganya yang terjangkau dan menyampingkan aspek kualitas. Pilihan-pilihan inilah yang menandakan adanya sebuah preferensi konsumen.

\section{Literature review}

Untuk menarik benang merah dari pendahuluan diatas, maka kata "selera" mempunyai arti yang sepadan untuk menggambarkan adanya preferensi konsumen, dimana ketika membahas tentang selera, maka kita akan dihadapkan pada berbagai macam hal yang mengerucut pada kata selera, seperti hobi, kondisi social, ekonomi serta sudut pandang lainnya. Preferensi yang dimiliki konsumen inilah yang pada akhirnya mempengaruhi pilihan mereka terhadap pembelian suatu merek yang melekat pada sebuah produk. Dengan kata lain, dengan preferensi konsumenlah yang pada akhirnya mempengaruhi pilihan mereka terhadap pembelian suatu merek, dan agar sebuah usaha dapat terus berjalan, maka seorang pengusaha harus mampu menganalisis preferensi dari target konsumennya.

Preferensi konsumen dapat diartikan sebagai sebuah factor kesukaan atas sebuah pilihan dari ketertarikan produk dan atau jasa (http://ciputrauceo.net, 2016), oleh karena itu, preferensi konsumen juga bisa dianggap sebagai sebuah bentuk perhatian berwujud pesan yang tidak hanya mengarah namun juga sudah mengendap dalam pikiran konsumen atas sebuah pemahaman dan ingatan konsumen tersebut terhadap produk atau jasa, sehingga konsumen tersebut akan menciptakan sebuah pola tingkah laku atas dasar preferensi yang terbentuk. Preferensi konsumen terhadap suatu barang dapat diketahui dengan menentukan atribut-atribut yang melekat pada sebuah produk atau jasa. Atribut-atribut itulah yang pada akhirnya dapat mempengaruhi 
seseorang sebagai pertimbangan untuk memilih suatu barang. Preferensi konsumen yang dimaksud dalam penelitian ini menggunakan kopi Wanaal sebagai obyek penelitian, Kopi Wanaal ini diproduksi sejak tahun 2016 dan diambil dari wilayah Papua di Pegunungan Tiom daerah sekitar kota Wamena, ada beberapa seri kopi dan berbeda, berdasarkan hasil wawancara dengan narasumber (Santo, 2019) yang mengatakan bahwa, pada dasarnya kopi merek wanaal ini bisa dibedakan dari empat seri utama yaitu:

1. Single origin Tiyom,

2. Single origin Oksibil,

3. four brothers (house blend) Sarmi, dan

4. Siandia (beans biji tunggal) Serui.

Dari keempat seri tersebut, kopi wanaal dapat ditemui meskipun masing-masing seri memiliki cita rasa yang berbeda-beda (chocolate, berry, nuty, citrus/asam). Pendiri dari Wanaal Kopi ini bernama Bapak Randi Manurung dan saat ini dikenal dengan Four brothers (house blend) Sarmi /Manurung Bersaudara. Lebih lanjut dalam wawancara tersebut, narasumber mengatakan Kopi Wanaal merupakan kopi yang termasuk dalam golongan jenis organik arabica yang mendekati sempurna dimana tingkat asam mendekati 0 dan antioksidan yang tinggi dibanding dengan kopi jenis lainnya. Pertama kali, kopi Wanaal ini dikemas dalam sebuah kemasan yang dijual denan berat bersih 200 gram dan seiring meningkatnya permintaan akan kopi jenis wanaal ini, maka pengusaha yang bersangkutan telah mengeluarkan dengan ukuran kemasan berat bersih $1 \mathrm{~kg}$. sejak itulah, kopi wanaal ini mulai diproduksi dan didistribusi yang dimulai dari dalam negeri sendiri dan sedang menjajaki kerjasama untuk ekspor. Walaupun ketenaran akan nama kopi wanaal papua ini belum begitu terdengar gaungnya akan tetapi sangat berpotensi menjadi aset yang luar biasa bagi wilayah papua itu sendiri. Saat ini seri four brothers belum menjadi penjualan paling tinggi karena:

1. Masalah quota/petani papua yang mulai melakukan pekerjaan lain selain petani kopi.

2. Seri Four brothers sendiri menggambarkan gabungan karakter beans dan juga gambaran gabungan karakter owner kopi jenis lainnya (selain Wanaal) yang menjadi satu dan menghasilkan image cita rasa yang belum kuat.

\section{Metode Penelitian}

Untuk menghasilkan sebuah informasi yang akurat maka pada tahap awal, sangat diperlukan adanya sebuah data yang menyangkut preferensi konsumen terhadap kopi wanaal tersebut, sehingga preferensi konsumen akan muncul didalam sebuah tahapan untuk menghasilkan sebuah keputusan pembelian, dimana dalam tahapan tersebut, konsumen dihadapkan pada berbagai macam pilihan produk maupun jasa dengan berbagai macam atribut yang berbeda-beda. Oleh karena itu, analisis conjoin dianggap tepat untuk memberikan gambaran peluang akan posisi produk dipasaran, sehingga tahapan preferensi tersebut dapat mewakili jawaban konsumen atas minatnya kepada kopi wanaal ini. Metode penelitian yang digunakan adalah studi kasus, yaitu strategi penelitian yang menyelidiki suatu program, peristiwa, aktivitas, proses atau sekelompok individu secara cermat (John W \& Achmad, 2010), penentuan responden menggunakan metode purposive sampling yaitu metode yang sesuai dengan tujuan penelitian ini. Sampel yang diambil sebanyak 100 orang responden, hal ini diambil agar dapat mebuat sebuah data yang dapat diolah untuk menentukan tingkat kepentingan relative berdasarkan persepsi konsumen yang dibawa oleh stau produk tertentu dan nilai kegunaan yang muncul dari atribut produk terkait. Disamping itu, untuk menentukan strategi pemasaran yang sesuai maka analisis conjoin inilah yang dianggap tepat dan baik (Santosa, 2019), untuk memperoleh hasil yang diharapkan, maka tahap awal yaitu membentu sebuah rumusan stimulus apa saja yang bisa berupa produk, merek atau barang yang akan dijual dipasar akan dievaluasi oleh konsumen sebagai suatu kumpulan atribut-atribut 
tertentu. Sehingga teknik ini bermanfaat dalam pemasaran untuk mengetahui preferensi konsumen terhadap suatu produk yang diluncurkan di pasar. Menurut Green dan Krieger dalam (Khrisna, 2013) menyebutkan bahwa analisis konjoin ini mempunyai manfaat utama dalam menentukan stratgei pemasaran yaitu merancang harga, selain merancang harga, analisis konjoin juga dianggap mampu untuk memprediksi tingkat penjualan atau penggunaan produk (market share) uji coba konsep produk baru, sehingga dapat merancang stratgei promosi yang baik dan pada akhirnya menentukan segmentasi preferensi. Atribut yang bisa diidentifikasikan serta preferensi bersifat additive merupakan asumsi dasar yang harus dibuat untuk memenuhi analisis konjoin, oleh karena itu analisis data yang digunakan untuk menguji data yang telah diperoleh menggunakan analisis conjoin yang secara matematis dijelaskan pada rumus berikut:

$$
r_{i}=\beta_{0}+\sum_{j=1}^{\rho} \mathrm{U}_{j k_{j i}}
$$

Keterangan:

$r_{i}=$ Kegunaan atau Utility Total

$\beta_{\mathrm{o}}=$ Intersep model respon $\sum_{\mathrm{j}=1}^{\rho} \mathrm{U} \mathrm{j}_{\mathrm{ji}}=$ Jumlah atribut dan utility dari faktor ke-j level ke $\mathrm{k}_{\mathrm{ji}}$

Kombinasi atribut yang digunakan adalah sebanyak $3^{3}$ dengan 3 atribut dengan masing-masing menggunakan 3 taraf kombinasi, kombinasi atribut tersebut diolah dalam bentuk kartu analisis conjoin yang memuat atribut atribut dan taraf-taraf atribut kombinasi berturut-turut sebagai berikut:

Tabel 1. Atribut Produk dan Tingkatan Utiliy

\begin{tabular}{|c|c|l|}
\hline \multirow{2}{*}{ ATRIBUT } & \multicolumn{2}{|c|}{ LEVEL } \\
\cline { 2 - 3 } & No & \multicolumn{1}{|c|}{ Keterangan } \\
\hline \multirow{4}{*}{ Cita Rasa } & 1 & Nikmat Manis \\
\cline { 2 - 3 } & 2 & Nikmat Standar \\
\cline { 2 - 3 } & 3 & Nikmat Pahit \\
\hline \multirow{4}{*}{ Aroma } & 1 & Tajam \& Khas \\
\cline { 2 - 3 } & 2 & Tajam \& Kurang Khas \\
\cline { 2 - 3 } & 3 & Kurang Tajam \& Kurang Khas \\
\hline \multirow{3}{*}{ Ampas Kopi } & 1 & Banyak \\
\cline { 2 - 3 } & 2 & Sedang \\
\cline { 2 - 3 } & 3 & Sedikit \\
\hline
\end{tabular}

Sumber: Data Olahan Peneliti

Output yang dihasilkan dalam penelitian ini memberikan batasan pada uji korelasi yang digunakan yaitu korelasi pearson, sehingga hipotesis yang dirumuskan dalam analisa conjoin ini adalah sebagai berikut:

Ho: tidak ada korelasi antara atribut produk terhadap prediksi

Ha: ada korelasi atribut produk terhadap terhadap prediksi

Sedangkan aturan keputusan adalah:

a. Jika nilai sig. hitung $\geq 0.05$ maka Ho diterima dan Ha ditolak

b. Jika nilai sig. hitung $\leq 0.05$ maka Ho ditolak dan Ha diterima 
Berdasarkan pada tabel 2, didapat 27 kombinasi stimuli yang sudah diberikan peringkatnya oleh 100 responden, urutan stimulus no 1 menandakan bahwa kombinasi stimuli itu paling banyak dipilih oleh para responden begitupun seterusnya, dari sini kita bisa melihat peringkat masing-masing produk di pasaran.

Tabel 2. Data Hasil Tingkatan Keseluruhan Pada Responden

\begin{tabular}{|c|c|c|c|c|}
\hline & Card ID & $\begin{array}{c}\text { Cita Rasa Yang } \\
\text { Diinginkan }\end{array}$ & Aroma Yang Diharapkan & $\begin{array}{c}\text { Ampas Kopi } \\
\text { Yang Dihasilkan }\end{array}$ \\
\hline 1 & 1 & Nikmat Manis & Tajam \& Khas & Sedang \\
2 & 2 & Nikmat Manis & Tajam \& Kurang Khas & Banyak \\
3 & 3 & Nikmat Manis & Tajam \& Kurang Khas & Sedikit \\
4 & 4 & Nikmat Manis & Tajam \& Kurang Khas & Sedang \\
5 & 5 & Nikmat Pahit & Tajam \& Khas & Banyak \\
6 & 6 & Nikmat Manis & Kurang Tajam \& Kurang Khas & Sedikit \\
7 & 7 & Nikmat Pahit & Tajam \& Kurang Khas & Banyak \\
8 & 8 & Nikmat Pahit & Kurang Tajam \& Kurang Khas & Sedang \\
9 & 9 & Nikmat Manis & Tajam \& Khas & Banyak \\
10 & 10 & Nikmat Standar & Tajam \& Kurang Khas & Sedang \\
11 & 11 & Nikmat Pahit & Tajam \& Kurang Khas & Sedang \\
12 & 12 & Nikmat Standar & Tajam \& Khas & Sedikit \\
13 & 13 & Nikmat Standar & Tajam \& Khas & Banyak \\
14 & 14 & Nikmat Pahit & Tajam \& Kurang Khas & Sedikit \\
15 & 15 & Nikmat Standar & Kurang Tajam \& Kurang Khas & Sedang \\
16 & 16 & Nikmat Standar & Kurang Tajam \& Kurang Khas & Sedikit \\
17 & 17 & Nikmat Standar & Tajam \& Khas & Sedang \\
18 & 18 & Nikmat Pahit & Kurang Tajam \& Kurang Khas & Sedikit \\
19 & 19 & Nikmat Pahit & Tajam \& Khas & Sedikit \\
20 & 20 & Nikmat Manis & Kurang Tajam \& Kurang Khas & Banyak \\
21 & 21 & Nikmat Manis & Tajam \& Khas & Sedikit \\
22 & 22 & Nikmat Manis & Kurang Tajam \& Kurang Khas & Sedang \\
23 & 23 & Nikmat Standar & Tajam \& Kurang Khas & Sedikit \\
24 & 24 & Nikmat Standar & Tajam \& Kurang Khas & Banyak \\
25 & 25 & Nikmat Pahit & Kurang Tajam \& Kurang Khas & Banyak \\
26 & 26 & Nikmat Pahit & Tajam \& Khas & Sedang \\
27 & 27 & Nikmat Standar & Kurang Tajam \& Kurang Khas & Banyak \\
\hline
\end{tabular}

Sumber: Data Olahan SPSS.18

\section{Hasil}

Tabel 3 menandakan bahwa data yang diperoleh bahwa 100 responden yang dijadikan sampel dalam penelitian ini setelah dilakukan penyebaran kuesioner maka dapat disimpulkan seperti dibawah ini

Tabel 3. Karakteristik Responden

\begin{tabular}{clc}
\hline No & \multicolumn{1}{c}{ Karakteristik } & Persentase (\%) \\
\hline 1 & Jenis kelamin & \\
& a. Laki-Laki & 60 \\
& b. Perempuan & 40 \\
& & \\
2 & Kelompok Umur & \\
& a. dibawah 30 tahun & 25 \\
& c. diatas 30 tahun & 75 \\
3 & Asal dan jenis kopi yang & \\
& biasa dikonsumsi
\end{tabular}




$\begin{array}{ll}\text { a. Single origin Tiyom } & 23 \\ \text { b. Single origin Oksibil, } & 17 \\ \text { c.four brothers (house } & \\ \quad \text { blend) Sarmi } & \\ \begin{array}{l}\text { d.Siandia (beans biji } \\ \text { tunggal) Serui. }\end{array} & 54\end{array}$

Sumber: data olahan.

\section{Nilai Utility}

Tabel 4 dibawah ini menyatakan nilai utility tertinggi dari para responden untuk memilih produk kopi wanaal berdasarkan atribut yang telah disusun, selain itu dari tabel 4 juga bisa dilihat masing-masing produk (berdasarkan atribut) akan mendapatkan kemungkinan potensi share pembelian kopi wanaal sesuai dengan nilai utility estimate yang didapatkan.

Tabel 4. Rata-rata Nilai Utiliy

\begin{tabular}{|ll|r|r|}
\multicolumn{4}{c|}{ Utilities } \\
\hline Cita_Rasa & Nikmat Manis & \multicolumn{1}{c|}{$\begin{array}{c}\text { Utility } \\
\text { Estimate }\end{array}$} & \multicolumn{1}{c|}{$\begin{array}{c}\text { Std. } \\
\text { Error }\end{array}$} \\
& Nikmat Standar &, 053 &, 178 \\
& Nikmat Pahit &,- 056 &, 178 \\
Aroma & Kurang Tajam \& Kurang Khas &, 002 &, 178 \\
& Tajam \& Kurang Khas &, 281 &, 154 \\
& Tajam \& Khas &, 561 &, 309 \\
Ampas_Kopi & Banyak &, 842 &, 463 \\
& Sedang &, 042 &, 154 \\
& Sedikit &, 084 &, 309 \\
(Constant) & & 127 &, 463 \\
& & 13,354 &, 454 \\
\hline
\end{tabular}

Sumber: Data Olahan SPSS.18

Terlihat didalam tabel tersebut, masing-masing nilai utility adalah variabel $\mathrm{X}_{\mathrm{ij}}$ atribut ke-i tingkatan ke-j dengan nilai konstanta didapat sebesar 13,354, maka model analisis conjoin yang didapat adalah sebagai berikut:

$r_{i}=13,354+0,053 \mathrm{x}_{11}-0,056 \mathrm{x}_{12}+0,002 \mathrm{x}_{13}+0,281 \mathrm{x}_{21}+0,561 \mathrm{x}_{22}+0,842 \mathrm{x}_{23}+0,042 \mathrm{x}_{31}+0.084$ $\mathrm{x}_{32}+0,127 \mathrm{x}_{33}$

Tabel 5. Rata-rata Nilai Importance

\begin{tabular}{|l|r|}
\multicolumn{2}{c}{ Importance Values } \\
\hline Cita_Rasa & 47,237 \\
Aroma & 27,584 \\
Ampas_Kopi & 25,180 \\
\hline
\end{tabular}

Sumber: Data Olahan SPSS 18

Pada tabel 5 diatas, dapat disimpulkan bahwa atribut cita rasa $(47,237 \%)$ merupakan atribut yang paling penting bagi para responden dalam menentukan preferensi konsumen terhadap kopi wanaal, selanjutnya adalah $27,584 \%$ untuk aroma dan $25,180 \%$ untuk atribut terakhir yaitu ampas kopi. Dan berdasarkan tabel korelasi dapat diketahui hubungan (korelasi) antara data responden 
dengan data sebenarnya yang bertujuan untuk mengukur ketepatan/kecocokan estimasi model. Output untuk nilai korelasi adalah sebagai berikut:

Tabel 6. Nilai Correlation

Correlationsa

\begin{tabular}{|l|r|r|}
\hline & \multicolumn{1}{|c|}{ Value } & \multicolumn{1}{c|}{ Sig. } \\
\hline Pearson's R &, 371 &, 029 \\
Kendall's tau &, 266 &, 026 \\
\hline
\end{tabular}

Sumber: Data Olahan SPSS.18

Pada tabel korelasi angka signifikan untuk uji Pearson's R dan Kendall's tau berada dibawah 0,05 maka kedua uji tersebut dikatakan layak dijadikan factor atribut untuk dilakukan uji dan sekaligus menandakan tingkat signifikan, dengan kata lain maka Ho diolak. Hal ini bearti memang terdapat korelasi yang nyata antara hasil konjoin dengan pendapat responden tersebut. Dengan demikian bahwa pendapat 100 responden tersebut dapat diterima sebagai gambaran bentuk upaya stimulus para responden untuk memilih jenis kopi wanaal karena dipengaruhi oleh tingkat aroma yang khas dari kopi jenis wanaal tersebut, sehingga diharapkan dapat bertahan dipasaran dan bersanding dengan jenis kopi setempat lainnya di Papua.

\section{Kesimpulan}

Dari hasil uji yang telah dilakukan dapat diambil beberapa kesimpulan bahwa Kopi jenis Wanaal Papua ini mempunyai potensi untuk masuk ke pasaran, karena aromanya yang khas. Selain itu atribut yang digunakan untuk mengukur preferensi konsumen pada kopi wanaal ini bisa menjadi komposisi pilihan yang sesuai untuk ditawarkan kepada konsumen. Dan pada akhirnya, Analisis conjoin yang dilakukan diatas sangat erat kaitannya dengan pendeskripsian jawaban yang dilakukan oleh responden untuk mengukur dengan terlebih dahulu menggunakan isian rating preference sehingga untuk jangka pendek ini, kopi wanaal ini dapat dipasarkan dengan komposisi cita rasa manis, ampas kopi yang sedikit dan sudah tentu dengan aroma yang tajam dan khas dari kopi wanaal itu sendiri.

\section{Daftar Referensi}

Ali, H. (2014). Marketing Dan Kasus - Kasus Pilihan. Yogyakarta: Center For Academic Publishing Service.

http://ciputrauceo.net. (2016, Mei 02). Preferensi Konsumen dan Tahapannya. Diambil kembali dari http://ciputrauceo.net: http://ciputrauceo.net/blog/2016/4/25/preferensi-konsumendan-tahapannya

Khrisna. (2013, Agustus 25). Analisis Konjoin. Diambil kembali dari http://datariset.com: http://datariset.com/analisis/detail/olah-data-jogja-contjoint-analysis

Santo. (2019, November 28). Sejarah Kopi Wanaal. (Elizabeth, Pewawancara)

Santosa, S. (2019). Analisa Analisa Konjoin : Upaya Stimulus Konsumen Untuk Mengkonsumsi Cemilan Franchaise Makanan Jagung Daily Fresh "Lapak Cinsong” Di Vihara Dhamma Bhakti, Jawaringan, Kab-Tangerang. ECo-Buss, 1-7. 